\title{
Diastolic Dysfunction and Left Ventricle Remodeling in Men with Impaired Fasting Glucose
}

\author{
Andrey Kratnov, Elena Timganova \\ Department of Therapy, Yaroslavl State Medical University, Yaroslavl, Russia \\ Email: kratnov@mail.ru
}

Received 14 June 2015; accepted 11 September 2015; published 14 September 2015

Copyright $@ 2015$ by authors and Scientific Research Publishing Inc.

This work is licensed under the Creative Commons Attribution International License (CC BY).

http://creativecommons.org/licenses/by/4.0/

(c) (i) Open Access

\begin{abstract}
Background: Early disturbances of carbohydrate metabolism are an independent risk factor of development of cardiovascular diseases. Objective: The diastolic dysfunction and left ventricle remodeling depending on presence of impaired fasting glucose were examined. Methods: The characteristics of heart remodeling and fasting glucose of capillary blood were studied in 85 men aged 30 to 63 years without coronary heart disease. Results: In male patients with impaired fasting glucose in comparison of persons with level of glucose less than $5.6 \mathrm{mM} / 1$, more pronounced diastolic dysfunction and left ventricle remodeling associated with more often presence III degree of peripheral obesity. Conclusion: Impaired fasting glucose in men increases probability of development of heart remodeling.
\end{abstract}

\section{Keywords}

\section{Early Disturbances of Carbohydrate Metabolism, Diastolic Dysfunction, Heart Remodeling}

\section{Introduction}

The difficulty of medical and economic consequences does prevention of type 2 diabetes mellitus by one of important directions in health care [1]. In recent years, for increase in efficiency of prevention of type 2 diabetes much attention is paid to timely revealing of early disturbances of carbohydrate metabolism, the presence of which is accompanied by an increase in the risk of death from cardiovascular disease [2]. Remodeling of heart resulting in change of geometry and infringement of contractility is also independent risk factor of cardiac death, acute myocardial infarction, stroke, ventricular arrhythmias, and heart failure [3] [4]. It is shown that an increase in the risk of development of heart failure is associated with growth of glycosylated hemoglobin levels indepen- 
dently of the presence of type 2 diabetes mellitus [5]. Fasting plasma glucose and glycosylated hemoglobin levels were positively correlated with the early diastolic filling ratio and the deceleration time of the $\mathrm{E}$ wave in nondiabetic patients with treated essential hypertension [6]. In the last years was shown, that experimental prediabetes can elicit structural remodeling in the left ventricle [7].

The purpose of this study was to examine the heart remodeling depending on presence of impaired fasting glucose in men without coronary heart disease.

\section{Participants and Methods}

\subsection{Participants}

We investigated 85 men aged 30 to 63 years (mean \pm SD age: $46.3 \pm 7.5$ years) which were hospitalized in hospital for professional survey. The study included men of working age; most of them had peripheral obesity, bad habits (smoking cigarettes and alcohol consumption) and family history of hypertension and obesity. In order to exclude coronary heart disease in all patients electrocardiography was performed, along with bicycle ergometry, Holter electrocardiography monitoring, and echocardiography. For the diagnosis of peripheral obesity, body mass index (BMI) was calculated. Exclusion criteria from the study were chronic alcoholism, disorders of thyroid function, anemia, type 2 diabetes mellitus, chronic inflammatory kidney disease, and malignant neoplasm.

\subsection{Methods}

This study was approved by the hospital's Ethics Committee, and all patients gave their written consent.

The sample of glucose of capillary blood was collected after a fast of at least 12 hours.

The echocardiography was carried out with use a Philips En Visor C (Bothell, USA). Left ventricular ejection fraction was assessed by semi-quantitative manner using the Biplane Simpson method. Patients with ejection fraction $<50 \%$, mitral valve surgery, and severe valvular disease were excluded. Diastolic function was assessed in a standardized method and in accordance with the most recently published guidelines by the European Association of Cardiovascular Imaging.

For diagnostics diastolic dysfunction we studied early ventricular filling (E-wave); late ventricular filling (A-wave); E/A ratio; isovolumic relaxation time (IVRT); E-wave peak velocity; E-wave deceleration time (EDT); A-wave duration. At the flow analysis by pulsed Doppler of the pulmonary veins have been received additional indices: flow systolic peak (S) — divided in S1 an S2-flow diastolic peak (D), atrial reverse flow peak (AR) and duration rate of this reverse flow (AR-dur) [8].

For revealing presence of left ventricle remodeling were defined: the mass of myocardium of the left ventricle, index of mass of myocardium of the left ventricle, and index of relative thickness of walls of the left ventricle. Various geometrical models of the left ventricle were allocated: normal geometry, eccentric hypertrophy, concentric remodeling, and concentric hypertrophy [9] [10].

\subsection{Statistical Analyses}

Statistical data processing was performed using the package Statistica 8.0 (StatSoft, Inc., USA). The data for categorical variables are expressed as absolute values and percents. Differences between groups were considered statistically significant at $P<0.05$.

\section{Results}

\subsection{Characteristics of the Study Participants}

The comparative characteristics of the study participants are presented in Table 1.

The level of capillary blood glucose $<5.6 \mathrm{mM} / \mathrm{l}$ was revealed in $62(72.9 \%)$ persons, the level of glucose 5.6 $6.1 \mathrm{mM} / \mathrm{l}$-in $16(18.8 \%)$, and the level of glucose $\geq 6.1 \mathrm{mM} / \mathrm{l}$-in 7 (8.3\%) patients. Obesity was encountered in 66 (77.6\%) evaluable patients, of whom $43(65.2 \%)$ revealed I degree (BMI $\left.30-34.9 \mathrm{~kg} / \mathrm{m}^{2}\right), 18(27.3 \%)-\mathrm{II}$ degree (BMI $35-39.9 \mathrm{~kg} / \mathrm{m}^{2}$ ), and 5 (7.5\%) patients-III degree of obesity (BMI $\left.\geq 40 \mathrm{~kg} / \mathrm{m}^{2}\right)$. In $72(84.7 \%)$ patients arterial hypertension was observed, among which 66 (91.7\%) men was with 1 degree and 6 (8.3\%) men was with 2 degrees of the disease. 
Obesity came to light more often in men with the level of capillary blood glucose $\geq 6.1 \mathrm{mM} / 1$. Among individuals with glucose levels $<5.6 \mathrm{mM} / \mathrm{l}$ compared of men with glucose levels 5.6 - $6.1 \mathrm{mM} / \mathrm{l}$ were found more often II degree of obesity (33.3\% $>9.1 \%, P=0.03$ ). III degree of obesity was diagnosed in patients with glucose level $\geq 5.6 \mathrm{mM} / 1$ more often.

Depending on the level of glycemia there were no significant differences in the frequency of occurrence of arterial hypertension. In men with the level of capillary blood glucose $5.6-6.1 \mathrm{mM} / \mathrm{l}$ the 2 degree of arterial hypertension met unreliable often.

\subsection{Diastolic Dysfunction and Left Ventricle Remodeling of the Study Participants}

Heart remodeling in dependence from level of fasting glucose of the capillary blood are presented in Table 2.

Diastolic dysfunction $(85.7 \%>45.2 \%, P=0.04)$ and left ventricle remodeling $(85.7 \%>35.5 \%, P=0.01)$ were detected significantly more frequently in men with the level of capillary blood glucose $\geq 6.1 \mathrm{mM} / 1$ in comparison of patients with levels $<5.6 \mathrm{mM} / \mathrm{l}$. In such patients more often the deficient relaxation $(100 \%>$ $57.1 \%, P=0.04)$ and concentric hypertrophy of left ventricular $(50 \%>13.6 \%, P=0.05)$ were diagnosed.

Heart remodeling also was observed more frequently in persons with the level of capillary blood glucose 5.6 $6.1 \mathrm{mM} / \mathrm{l}$. Diastolic dysfunction $(62.5 \%>45.2 \%)$ and left ventricle remodeling $(56.3 \%>35.5 \%)$ in these patients were found more often in comparison of men with glucose levels $<5.6 \mathrm{mM} / \mathrm{l}$. Concentric hypertrophy of left ventricular in persons with glucose 5.6 - $6.1 \mathrm{mM} / \mathrm{l}$ were diagnosed more frequently $(33.3 \%>13.6 \%)$.

\section{Discussion}

In recent years, because of the high prevalence and early invalidity the type 2 diabetes mellitus has become a serious medico-social problem. Often the diagnosis of this disease is established when the most of patients are already having macro- and microvascular complications [11]. Therefore, the early disturbances of carbohydrate metabolism which are predictors of development of type 2 diabetes mellitus became the object of close attention of scientists. Impaired glucose tolerance, impaired fasting glucose, and their combination belong to early disturbances of carbohydrate metabolism or "prediabetes" [12].

Table 1. Comparative characteristics of the study participants in dependence from level of glycemia.

\begin{tabular}{|c|c|c|c|}
\hline & $<5.6 \mathrm{mM} / \mathrm{l}(\mathrm{n}=62)$ & $5.6-6.1 \mathrm{mM} / \mathrm{l}(\mathrm{n}=16)$ & $\geq 6.1 \mathrm{mM} / \mathrm{l}(\mathrm{n}=7)$ \\
\hline Obesity: & $48(77.4)$ & $11(68.8)$ & $7(100)$ \\
\hline I degree & $30(62.5)$ & $8(72.7)$ & $5(71.4)$ \\
\hline II degree & $16(33.3)$ & $1(9.1)$ & $1(14.3)$ \\
\hline III degree & $2(4.2)$ & $2(18.2)$ & $1(14.3)$ \\
\hline Arterial hypertension: & $52(83.8)$ & $14(87.5)$ & $6(85.7)$ \\
\hline 1 degree & $49(94.2)$ & $11(78.6)$ & $6(100)$ \\
\hline 2 degree & $3(5.8)$ & $3(21.4)$ & $0(0)$ \\
\hline
\end{tabular}

Table 2. Heart remodeling of the study participants in dependence from level of glycemia.

\begin{tabular}{|c|c|c|c|}
\hline & $<5.6 \mathrm{mM} / \mathrm{l}(\mathrm{n}=62)$ & $5.6-6.1 \mathrm{mM} / \mathrm{l}(\mathrm{n}=16)$ & $\geq 6.1 \mathrm{mM} / \mathrm{l}(\mathrm{n}=7)$ \\
\hline Diastolic dysfunction: & $28(45.2)$ & $10(62.5)$ & $6(85.7)$ \\
\hline deficient relaxation & $16(57.1)$ & $7(70)$ & $6(100)$ \\
\hline pseudonormal & $12(42.9)$ & $3(30)$ & $0(0)$ \\
\hline Left ventricle remodeling: & $22(35.5)$ & $9(56.3)$ & $6(85.7)$ \\
\hline concentric remodeling & 19 (86.4) & $6(66.7)$ & $3(50)$ \\
\hline concentric hypertrophy & $3(13.6)$ & $3(33.3)$ & $3(50)$ \\
\hline
\end{tabular}


The probability of identification of early disturbances of carbohydrate metabolism higher in patients with obesity, arterial hypertension and clinical manifestations of atherosclerosis is observed. According to British scientists, the impaired fasting glucose came to light not less than in $10 \%$ of patients with arterial hypertension [13]. In this study in individuals with impaired fasting glucose more often than in patients with a normal glycemia, III degree of obesity and II degree of arterial hypertension was revealed. Probably, the combination of hereditary predisposition to diabetes (PTPN1 gene), a high degree of obesity and arterial hypertension leads to increased of cases of heart remodeling in patients with impaired fasting glucose in comparison of men with glucose level < $5.6 \mathrm{mM} / \mathrm{l}$.

In men with impaired fasting glucose the important contribution to more often development of heart remodeling brings III degree of peripheral obesity. It is known, that the higher remote cardiovascular risk, as well as risk of death from all reasons, is observed generally in persons with expressed obesity [14]. The increase in degree of obesity is accompanied by growth of the content of free fatty acids in the system circulation. The free fatty acids interfere the binding of insulin with hepatocytes that leads to development of hyperinsulinemia and also break the absorption and utilization of glucose in muscular tissue with development of a peripheral insulinresistance [15]. Growth of concentration of free fat acids in blood increases their availability for cardiomyocytes. The free fatty acids inhibit the oxidation of glucose in a myocardium [16]. Though fatty acids are more preferable substratum for cardiomyocytes, the energy received at oxidation of glucose is necessary for maintenance of the certain cellular functions. Disturbance of carbohydrate oxidation and increase in the rate of oxidation of fatty acids in a myocardium is an important factor in the violation of contractile function of a myocardium [17]. In experiment it is also shown, that the increase in concentration of fatty acids in a myocardium is accompanied by growth of protein content of the coupling which participates in reduction process of cardiomyocytes [18]. Also there are proofs, that factors secreted by epicardial adipose tissue (activin A) exert paracrine effects on cardiac metabolism and contractile function of the left ventricle [19].

The pathophysiological mechanism promoting to the development of arterial hypertension and heart remodeling in individuals with obesity is the activation of sympathetic nervous system. The increase in transfer of nervous impulses on sympathetic fibers can be caused as hyperinsulinemia, and increase the content of leptin in blood plasma, the concentration of which directly correlates with the degree of obesity [20] [21]. Hyperactivation of sympathetic nervous system makes the important contribution to progressing of heart remodeling [22].

\section{Conclusion}

This study demonstrated that in men with impaired fasting glucose compared to individuals with fasting glucose levels $<5.6 \mathrm{mM} / \mathrm{l}$ is more often diagnosed diastolic dysfunction and left ventricle remodeling.

\section{References}

[1] Straka, R.J, Liu, L.Z., Girase, P.S., DeLorenzo, A. and Chapman, R.H. (2009) Incremental Cardiovascular Costs and Resource Use Associated with Diabetes: An Assessment of 29,863 Patients in the US Managed-Care Setting. Cardiovascular Diabetology, 8, 53. http://dx.doi.org/10.1186/1475-2840-8-53

[2] The DECODE study group on behalf of the Europe an Diabetes Epidemiology Group (1999) Glucose Tolerance and Mortality: Comparison of WHO and American Diabetes Association Diagnostic Criteria. Lancet, 354, 617-621. http://dx.doi.org/10.1016/S0140-6736(98)12131-1

[3] Vakili, B.A., Okin, P.M. and Devereux, R.B. (2001) Prognostic Implications of Left Ventricular Hypertrophy. American Heart Journal, 141, 334-341. http://dx.doi.org/10.1067/mhj.2001.113218

[4] Galderisi, M., Anderson, K.M., Wilson, P.W. and Levy, D. (1991) Echocardiographic Evidence for the Existence of a Distinct Diabetic Cardiomyopathy (the Framingham Heart Study). American Journal Cardiology, 68, 85-89. http://dx.doi.org/10.1016/0002-9149(91)90716-X

[5] Chae, C.U., Glynn, R.J., Manson, J.E., Guralnik, J.M., Taylor, J.O. and Pfeer, M.A. (1998) Diabetes Predicts Congestive Heart Failure Risk in the Elderly. Circulation, 98, 721.

[6] Miyazato, J., Horio, T., Takishita, S. and Kawano, Y. (2002) Fasting Plasma Glucose Is an Independent Determinant of Left Ventricular Diastolic Dysfunction in Nondiabetic Patients with Treated Essential Hypertension. Hypertension Research, 25, 403-439. http://dx.doi.org/10.1291/hypres.25.403

[7] D’Souza, A., Howarth, F.C., Yanni, J., Dobryznski, H., Boyett, M.R., Adeghate, E., Bidasee, K.R. and Singh, J. (2011) Left Ventricle Structural Remodelling in the Prediabetic Goto-Kakizaki Rat. Experimental Physiology, 96, 875-888. http://dx.doi.org/10.1113/expphysiol.2011.058271 
[8] Nagueh, S.F., Appleton, C.P., Gillebert, T.C., Marino, P.N., Oh, J.K., Smiseth, O.A., Waggoner, A.D., Flachskampf, F.A., Pellikka, P.A. and Evangelista, A. (2009) Recommendations for the Evaluation of Left Ventricular Diastolic Function by Echocardiography. European Journal of Echocardiography, 10, 165-193. http://dx.doi.org/10.1093/ejechocard/jep007

[9] Lang, R. M., Bierig, M., Devereux, R.B., Flachskampf, F.A., Foster, E., Pellikka, P.A., Picard, M.H., Roman, M.J., Seward, J., Shanewise, J., Solomon, S., Spencer, K.T., St John, Sutton, M. and Stewart, W. (2006) Recommendations for Chamber Quantification. European Journal of Echocardiography, 7, 79-108. http://dx.doi.org/10.1016/j.euje.2005.12.014

[10] Ganau, A., Devereux, R.B., Roman, M.J., de Simone, G., Pickering, T.G., Saba, P.S., Vargiu, P., Simongini, I. and Laragh, J.H. (1992) Patterns of Left Ventricular Hypertrophy and Geometric Remodeling in Essential Hypertension. Journal of the American College of Cardiology, 19, 1550-1558. http://dx.doi.org/10.1016/0735-1097(92)90617-V

[11] Buse, J.B., Ginsberg, H.N., Bakris, G.L., Clark, N.G., Costa, F., Eckel, R., Fonseca, V., Gerstein, H.C., Grundy, S., Nesto, R.W., Pignone, M.P., Plutzky, J., Porte, D., Redberg, R., Stitzel, K.F. and Stone, N.J. (2007) Primary Prevention of Cardiovascular Diseases in People with Diabetes Mellitus: A Scientific Statement from the American Heart Association and the American Diabetes Association. Circulation, 115, 114-126. http://circ.ahajournals.org/cgi/content/full/115/1/114 http://dx.doi.org/10.1161/CIRCULATIONAHA.106.179294

[12] Qiao, Q., Lindstrom, J., Valle, T.T. and Tuomilehto, J. (2003) Progression to Clinically Diagnosed and Treated Diabetes from Impaired Glucose Tolerance and Impaired Fasting Glycaemia. Journal of British Diabetic Association, 20, 1027-1033. http://dx.doi.org/10.1111/j.1464-5491.2003.01054.x

[13] De Fronzo, R.A., Ferrannini, E., Keen, H. and Zimmet, P. (2004) International Textbook of Diabetes Mellitus (Third Edition). John Wiley \& Sons, Hoboken. http://www3.interscience.wiley.com/cgi-bin/mrwhome/104554815/HOME?

[14] Romero-Corral, A., Montori, V.M., Somers, V.K., Korinek, J., Thomas, R.J., Allison, T.G., Mookadam, F. and Lopez-Jimenez, F. (2006) Association of Bodyweight with Total Mortality and with Cardiovascular Events in Coronary Artery Disease: A Systematic Review of Cohort Studies. Lancet, 368, 666-678. http://dx.doi.org/10.1016/S0140-6736(06)69251-9

[15] Haslam, D.W. and James, W.P. (2005) Obesity. Lancet, 366, 1197-1209. http://dx.doi.org/10.1016/S0140-6736(05)67483-1

[16] Ussher, J.R. and Lopaschuk, G.D. (2006) Clinical Implications of Energetic Problems in Cardiovascular Disease. Heart and Metabolism, 32, 9-17. heartandmetabolism.org>download/32/3.pdf

[17] Paolisso, G., Gambardella, A., Galzerano, D., D’Amore, A., Rubino, P., Verza, M., Teasuro, P., Varricchio, M. and D’Onofrio, F. (1994) Total-Body and Myocardial Substrate Oxidation in Congestive Heart Failure. Metabolism, 43, 174-178. http://dx.doi.org/10.1016/0026-0495(94)90241-0

[18] Boudina, S., Sena, S., Theobald, H., Sheng, X., Wright, J.J., Hu, X.X., Aziz, S., Johnson, J.I., Bugger, H., Zaha, V.G. and Abel, E.D. (2007) Mitochondrial Energetics in the Heart in Obesity-Related Diabetes: Direct Evidence for Increased Uncoupled Respiration and Activation of Uncoupling Proteins. Diabetes, 56, 2457-2466. http://dx.doi.org/10.2337/db07-0481

[19] Chen, W.J.Y., Greulich, S., van der Meer, R.W., Rijzewijk, L.J., Lamb, H.J., de Roos, A., Smit, J.W.A., Romijn, J.A, Ruige J.B., Lammertsma, A.A., Lubberink, M., Diamant, M. and Ouwens, D.M. (2013) Activin a Is Associated with Impaired Myocardial Glucose Metabolism and Left Ventricular Remodeling in Patients with Uncomplicated Type 2 Diabetes. Cardiovascular Diabetology, 12, 150. http://www.cardiab.com/content/12/1/150 http://dx.doi.org/10.1186/1475-2840-12-150

[20] Blum, W.F., Englaro, P., Hanitsch, S., Juul, A., Hertel, N.T., Muller, J., Skakkebaek, N.E., Heiman, M.L., Birkett, M., Attanasio, A.M., Kiess, W. and Rascher, W. (1997) Plasma Leptin Levels in Healthy Children and Adolescents: Dependence on Body Mass Index, Body Fat Mass, Gender, Pubertal Stage and Testosterone. The Journal of Clinical Endocrinology \& Metabolism, 82, 2904-2910.

[21] Matsumura, K., Abe, I., Tsuchihashi, T. and Fujishima, M. (2000) Central Effects of Leptin on Cardiovascular and Neurohormonal Responses in Conscious Rabbits. American Journal of Physiology - Regulatory, Integrative and Comparative Physiology, 278, R1314-R1320.

[22] Francis, G.S., Goldsmith, S.R., Levine, T.B., Olivari, M.T. and Cohn, J.N. (1984) The Neurohumoral Axis in Congestive Heart Failure. Annals of Internal Medicine, 101, 370-377. http://dx.doi.org/10.7326/0003-4819-101-3-370 